\title{
MAPEAMENTO DE CARACTERÍSTICAS FÍSICAS DO RE- LEVO DA CIDADE DE GUARAPUAVA-PR UTILIZANDO TÉCNICAS DE GEOPROCESSAMENTO
}

\section{Relief physical features screening of Guarapuava-PR through geoprocessing techniques}

\author{
Andrey Luis Binda ${ }^{1}$ \\ Luiz Gilberto Bertotti ${ }^{2}$
}

\begin{abstract}
RESUMO
O relevo é o principal agente físico que interfere a ocupação urbana. Normalmente, essa se inicia em áreas mais favoráveis e, somente depois, com a expansão urbana acabam ocupando áreas impróprias. É neste viés que se insere a presente pesquisa, visando elaborar um estudo integrado das características físicas do relevo no perímetro urbano da cidade de Guarapuava-PR. Para isso utilizou-se de três procedimentos metodológicos: pesquisa bibliográfica; trabalhos de campo e trabalhos de laboratório/gabinete. Com o auxílio de técnicas de geoprocessamento e utilização do software SPRING versão 4.3.3, foram realizados mapeamentos para cada variável (hidrografia e bacias hidrográficas urbanas, hipsometria, declividade, exposição de vertentes, solos e formas de relevo). Conhecer as características físicas do espaço urbano, as limitações e as potencialidades torna-se de grande valia para o estabelecimento de práticas mais racionais de uso do solo e de um planejamento urbano mais condizente com tais especificidades.
\end{abstract}

Palavras-chave: Geoprocessamento; relevo; ocupação urbana; degradação ambiental.

\begin{abstract}
The relief is the main physical agent that interferes with human occupation. Normally, occupation begins in favorable areas and only later, with the urban expansion, it extends to unfavorable ones. In this context, this work aims at elaborating an integrated study of the relief physical features of Guarapuava-PR urban perimeter. Three methodological procedures were used: bibliographic research, field and laboratory/cabinet works. Screening of several variables (hydrography and urban river basin, hipsometry, declivity, source exposition, relief soil and shape) was performed through geoprocessing techniques using SPRING version 4.3.3 software. The knowledge of urban space physical features, limitations and potentialities is important to establish more reasonable actions regarding soil usage and to make urban planning that fits better such specifity.
\end{abstract}

Keywords: Geoprocessing; relief; urban occupation; environmental degradation.

1 Licenciado e Bacharel em Geografia pela Universidade Estadual do Centro-Oeste-Unicentro; Discente do Programa de Pós-Graduação em Geografia - Nível Mestrado - da Universidade Estadual do Oeste do Paraná-Unioeste Bolsista da DS da Capes. E-mail: andrey_geobass@ hotmail.com (Universidade Estadual do Oeste do Paraná - Unioeste - Fco Beltrão - PR)

2 Professor Adjunto do Departamento de Geografia da Universidade Estadual do Centro-Oeste-Unicentro. Pesquisador do Núcleo de Pesquisas Ambientais - NPA/Unicentro. E-mail: bertotti@unicentro.br (Universidade Estadual do Centro Oeste - Unicentro - Guarapuava $-\mathrm{PR})$ 
BINDA, L. A.; BERTOTTI, G. L. Mapeamento de características físicas do relevo da cidade de Guarapuava-PR...

\section{INTRODUÇÃO}

A ocupação do relevo no ambiente urbano acarreta diversas mudanças nas características físico-naturais das encostas, muitas vezes essas alterações trazem consigo diferentes formas de degradação ambiental.

Conhecer as características físicas do espaço urbano, as limitações e as potencialidades torna-se de grande valia para o estabelecimento de práticas mais racionais de uso da terra e de um planejamento urbano mais condizente com tais especificidades. Além disso, devem-se também reconhecer os processos de degradação ambiental e os riscos geomorfológicos decorrentes da ocupação das vertentes, fatores importantes a fim de procurar estabelecer medidas preventivas e/ ou corretivas.

E é neste contexto que se insere o presente artigo, o qual busca realizar um estudo das características físicas do relevo da cidade de Guarapuava-PR, por meio da elaboração de diferentes cartas temáticas (hidrografia e bacias hidrográficas urbanas, hipsometria, declividade, exposição de vertentes, solos e formas de relevo), utilizando técnicas de geoprocessamento.

Dessa forma, inicia-se este artigo com a descrição da metodologia utilizada para a execução desta pesquisa, focando, sobretudo, as técnicas de geoprocessamento desde a importação de dados até a geração de produtos cartográficos. Num segundo momento, são descritas as características gerais do município de Guarapuava. Logo a seguir são apresentados os resultados e a discussão propositiva.

\section{MÉTODOS E TÉCNICAS}

Para atingir os objetivos propostos para a presente pesquisa, pautou-se nos seguintes passos metodológicos: revisão bibliográfica, trabalho de gabinete e trabalho de campo, os quais são melhores explicados a seguir.

\section{a) Revisão Bibliográfica}

Esta etapa consiste na fundamentação teórica da pesquisa, com consultas em livros, revistas e trabalhos de mesma natureza. Isto permite verificar a importância da aplicação de determinadas técnicas de trabalho, tão bem quanto, a utilização de termos e linguagem adequada.

b) Trabalho de Gabinete

Esta etapa é dividida em duas fazes:

- Compilação de Dados
Consiste na reunião das informações necessárias à execução da pesquisa, ou seja, a compilação de dados de diferentes naturezas (bibliográfica, cartográficos, entre outros), e a escolha dos dados mais significativos para a pesquisa.

- Trabalho em Laboratório

Para a execução desta pesquisa, utilizou-se de técnicas de geoprocessamento que, para Teixeira e Christofoletti (1997, p.121), consiste na "tecnologia que abrange o conjunto de procedimentos de entrada, manipulação, armazenamento e análise de dados espacialmente referenciados".

Os softwares utilizados nesta pesquisa foram:

- SPRING - INPE@ Versão 4.3.3 - Sistema de Processamento de Informações Georreferenciadas (Copyright - Instituto Nacional de Pesquisas Espaciais - INPE), desenvolvido pela Divisão de Processamento de Imagens - DPI do Instituto Nacional de Pesquisas Espaciais (INPE).

- Google Earth versão 4.0.2416 (beta) desenvolvido pela Google $₫$;

- AutoDesk Map versão 2002 desenvolvido pela Autodesk ${ }^{\circledR}$.

Os dados cartográficos utilizados foram:

- Cartas topográficas: Guarapuava (Folha SG. 22-V-D-III-3 MI2838/3) e Guarapuava (Folha SG.22-VD-II-4 MI-2837/4); escala: 1:50.000; (eqüidistância das curvas de nível: 20 metros);

- Mapa Temático de Coberturas Inconsolidadas, realizado em 1992, pela Minerais do Paraná (Mineropar) para o perímetro urbano de Guarapuava daquela época;

- Dados vetoriais (hidrografia, curvas de nível com eqüidistância de $5 \mathrm{~m}$ e sistema viário), disponíveis em meio digital no Format Drawing Web (DWG) do Levantamento Aerofotogramétrico Cadastral de 1996 - Escala 1:2.000, Vôo 1:8.000 de Out/1995, contratado pelo Município de Guarapuava, por meio de Convênio com a Sedu/Paranacidade e executado por consórcio pelas Empresas de Aerofotogrametria Engefoto e Aeroimagem e suas atualizações executadas pela Prefeitura Municipal de Guarapuava por levantamentos topográficos e arquivos de loteamentos aprovados.

- Pranchas Analógicas do levantamento Aerofotogramétrico Cadastral de 1986 - Escala de 1:2.000, Vôo 1:8.000, contratado pelo Município e executado pela Empresa de Aerofotogrametria - Engefoto, com curvas de nível de eqüidistância de $5 \mathrm{~m}$.

c) Trabalho de Campo

Teve como objetivo verificar a veracidade dos 
BINDA, L. A.; BERTOTTI, G. L. Mapeamento de características físicas do relevo da cidade de Guarapuava-PR...

documentos e dados manipulados nas etapas anteriores.

\section{PROCEDIMENTOS EM LABORATÓRIO}

Neste trabalho optou-se por utilizar o software SPRING versão 4.3.3. como ferramenta de entrada e manipulação de dados. Dessa forma, criou-se um banco de dados em que seriam inseridas as informações vetoriais e matriciais. O banco de dados no software SPRING corresponde a um diretório em que são gravadas todas as informações e definições do projeto, categorias e classes.

Criado o banco de dados estabeleceram-se os valores do projeto. O projeto refere-se à área física do trabalho, correspondente a um retângulo envolvente (área do projeto) e informações de projeções. Dessa forma, criou-se o projeto inserindo as seguintes informações:

- Projeção: UTM/SAD 69;

- Meridiano Central: $51^{\circ} \mathrm{W}$;

- Zona: 22;

- Área do projeto (retângulo envolvente): X1: 435000, X2: 465000, Y1: 7180000 e Y2: 7202000.

Uma vez criado o projeto, já podem ser instituídos os modelos de dados conforme sua natureza (categoria): temático, modelo numérico do terreno (MNT), imagem, rede, cadastral, objeto e não espacial. Dentro de cada modelo de dados são criados os Planos de Informação (PI's) que correspondem aos layers do trabalho.

\section{ENTRADA DE DADOS NO SPRING}

a) Entrada de Dados no Formato Grib (Griddeb Binary)

As primeiras informações inseridas no banco de dados deste trabalho foram às cartas topográficas. Essas cartas foram escaneadas em scanner de mesa, e salvas no formato Tiff. Para o armazenamento de imagens, o SPRING utiliza dados no formato Grib. Sua conversão é feita por meio do módulo IMPIMA, onde é informada as suas dimensões e a resolução da imagem (pixel x pixel). Uma vez salva no formato Grib, essa imagem já pode ser inserida no respectivo modelo de dados de natureza imagem.

As imagens no formato Grib, antes de serem inseridas no SPRING, passaram por um processo de georreferenciamento (registro de imagem) no próprio SPRING pela aquisição de pontos de controle via teclado, ou seja, com uma carta topográfica analógica, retirava-se às coordenadas UTM (de preferência as referentes às interseções das quadrículas), sendo estas inseridas como coordenadas de referência no software, cada ponto era ajustado (por meio da Tela 5) na respectiva coordenada. Para cada carta topográfica foram levantados 9 pontos de controle, os quais eram posteriormente selecionados e salvos.

Somente após ter salvado os pontos de controle é que a imagem pode ser inserida no SPRING, pela função Importar Arquivos Grib. A imagem inserida é composta por 3 bandas que correspondem aos canais de tons vermelho $(R)$, verde $(G)$ e azul $(B)$. Este procedimento foi adotado também para o mapa de coberturas inconsolidadas (MINEROPAR, 1992).

Após ter sido registrada as duas cartas topográficas realizou-se o mosaico de maneira a torná-las uma única imagem. Feito isso iniciou-se a digitalização das informações referentes à hidrografia e curvas de nível, de modo a satisfazer os limites atuais do perímetro urbano de Guarapuava. Para os rios, foi criado um modelo de dados temático, e sua digitalização se fez pela função Edição vetorial. Para as curvas de nível foi criado um modelo de dados numérico (MNT) e sua edição foi realizada, sempre inserindo a cota (valor de Z) para cada linha ou ponto digitalizado.

Essas duas informações foram as primeiras a serem trabalhadas, embora tenham sido originadas em cartas topográficas na escala de 1:50.000, elas foram fundamentais, por ser o único documento disponível, que cobria o perímetro urbano e as áreas adjacentes.

b) Entrada de Dados no Formato DXF-R12

Os Dados vetoriais das restituições realizadas pela Engefoto/Aeroimagem por de fotos do ano de 1996 encontravam-se no formato dwg do AutoCad. Para estes arquivos serem utilizados no software SPRING, foi necessário salvá-los no formato DXF-R12, formato este passível de ser manipulado no SPRING.

O processo de importação de dados no formato DXF-R12 para o software SPRING, se fez por meio da função Importar... no qual deve-se informar o formato (neste caso DXF-R12) e o layer a ser importado. No entanto, antes da importação dos layers devem ser criados modelos de dados apropriados para cada informação. Os dados importados quando devidamente georreferenciados ajustam-se automaticamente ao projeto do trabalho.

Por meio desse procedimento foram importadas as seguintes informações temáticas: rios, terrenos alagadiços, lagos e lagoas, malha urbana, perímetro urbano, estradas de rodagem (BR-277, PR-170 e PR466) e ferrovia. As curvas de nível e os pontos cotados 
BINDA, L. A.; BERTOTTI, G. L. Mapeamento de características físicas do relevo da cidade de Guarapuava-PR...

foram importados como modelos numéricos de terreno (MNT).

Os layers, curvas de nível (eqüidistância $5 \mathrm{~m}$ ) e pontos cotados foram às informações mais importantes para a presente pesquisa, visto que foi por meio destas que gerou-se alguns produtos cartográficos, tais como a carta de declividade, de hipsometria e de exposição de vertentes. Dessa forma, a seguir serão descritos de forma específica os procedimentos relacionados à importação, ajustes e geração das grades triangular (TIN) e retangular.

\section{PROCEDIMENTOS PARA ELABORAÇÃO DE PRO- DUTOS CARTOGRÁFICOS}

a) Curvas de Nível e Geração das Grades Triangular e Retangular

As curvas de nível e os pontos cotados foram importadas do arquivo que continha as restituições na escala de 1: 2.000 e de 1: 5.000 que abrangiam o perímetro urbano do ano de 1996.

No entanto, as curvas de nível, ao serem importadas além de não possuírem o valor das cotas atribuídas (possuíam a cota Z, mas em formato texto, e não como informação de atributo dentro do arquivo digital), algumas estavam quebradas ou duplicadas (apesar de estarem em formato digital, baseava-se apenas em um arquivo tipo CAD e não editado para uso em geoprocessamento). Graças a isso, após serem importadas, verificaram-se todas as linhas juntando e concatenando quando necessário. No que tange aos pontos cotados, estes não necessitaram a inserção dos valores de $Z$ vistos que já possuíam cotas no próprio arquivo Drawing.

Após esta operação, notou-se que as curvas de nível e pontos cotados não cobriam todo o atual perímetro urbano. Isto se deve ao fato de que no ano de restituição das fotos aéreas o perímetro urbano da sede de Guarapuava era distinto do atual. Em conseqüência a isto, buscou-se atualizar as curvas de nível (a fim de se procurar complementar os dados o máximo possível até os limites do perímetro urbano atual) por documentos cartográficos analógicos correspondente ao levantamento aerofotogramétrico de 1986, na escala de 1:2.000. Nos locais em que não havia cobertura de documentos cartográficos na escala desejada (1:2.000), utilizou-se das curvas de nível digitalizadas sobre a carta topográfica (eqüidistância de $20 \mathrm{~m}$ ). As interpolações das curvas foram feitas visualmente, sendo as mesmas conferidas nas imagens do software Google Earth pela visualização tridimensional do relevo e das cotas altimétricas, devidamente ajustadas e convertidas à projeção UTM, SAD-69. Completadas todas as curvas de nível, utilizou-se da função Suavização de Linhas, com o objetivo de tornar suaves as bordas abruptas das curvas (que são geradas por meio da restituição por sistemas digitais). Depois de suavizadas as linhas iniciou-se o processo de geração das grades.

\section{GRADE RETANGULAR}

A grade retangular ou regular é um modelo digital que aproxima superfícies por meio de um poliedro de faces retangulares" (SPRING, 2005, p. 07). Para a sua geração foi utilizada as amostras (curvas de nível suavizadas e pontos cotados), e a resolução ${ }^{3}$ inserida foi de $5 \times 5$.

\section{GRADE TRIANGULAR (TIN)}

A grade triangular ou simplesmente grade TIN (Triangular Irregular Network), consiste na criação de inúmeros triângulos, os quais:

permite que as informações morfológicas importantes como as descontinuidades, representadas por feições lineares de relevo (cristas) e drenagem (vales), sejam consideradas durante a geração da grade triangular, possibilitando assim modelar a superfície do terreno preservando as feições geomórficas da superfície (SPRING, 2005, p. 5).

Para sua elaboração utilizou-se da função Geração da grade triangular, na qual se deve entrar com as amostras das curvas de nível (suavizadas) e pontos cotados, estabelecendo-se também outros parâmetros, como por exemplo, o cruzamento com outro plano de informação (linhas de quebra), sendo usualmente usada a hidrografia. Com a grade TIN, podem-se gerar mapas de declividade e exposição de vertentes.

\section{PROCEDIMENTO PARA ELABORAÇÃO DE CARTAS TEMÁTICAS}

a) Geração da Carta de Hidrografia e Bacias Hidrográficas Urbana

A carta de hidrografia e bacias hidrográficas urbana foi realizada pela importação dos dados do levantamento planialtimétrico de Guarapuava (1996) e

3 Segundo XAVIER DA SILVA (1995) as resoluções mínimas aceitáveis correspondem a: $2.500 \mathrm{~m}^{2}$ (50 × 50m) para escalas de 1:100.000 e $625 \mathrm{~m}^{2}(25 \times 25 \mathrm{~m})$ para escalas de 1:50.000, escalas de maiores detalhes devem seguir esta lógica. 
BINDA, L. A.; BERTOTTI, G. L. Mapeamento de características físicas do relevo da cidade de Guarapuava-PR...

posterior digitalização e atribuições de classes temáticas. Assim, para a hidrografia do perímetro urbano de Guarapuava estabeleceram-se quatro classes temáticas, quais sejam: 1) rios intermitentes, 2) rios perenes, 3) lagoas e lagos e 4) várzea.

Para a individualização das bacias hidrográficas utilizou-se das curvas de nível e pontos cotados. Dessa forma, dividiu-se o perímetro urbano de Guarapuava, em quatro classes temáticas cada uma representando uma bacia hidrográfica: Rio Cascavel, Rio Coutinho, Rio Jordão e Rio das Mortes/Pedras.

\section{b) Geração da Carta de Hipsometria}

A carta de hipsometria foi gerada a partir da grade retangular. Para realização da carta de hipsometria, deve-se conhecer a cota mínima e máxima da área de estudo, ou seja, a menor e a maior altitude. Assim, deve-se criar um modelo de dados de natureza temática, inserindo as classes temáticas da hipsometria. Para o presente estudo utilizou-se de 13 classes de hipsometria com eqüidistância de 20 m entre elas: 920-940, 940-960, 960-980, 980-1000, 1000-1020, 1020-1040, 1040-1060, 1060-1080, 1080-1100, 1100-1120, 1120-1140, 11401160 e $>1160 \mathrm{~m}$. A variável visual utilizada para representar cada classe temática foi à cor, ou seja, para cada intervalo de classes utilizou-se uma cor diferenciada, conforme o quadro a seguir (Quadro 1):

\begin{tabular}{|c|c|}
\hline $\begin{array}{c}\text { Classes } \\
\text { hipsométricas }\end{array}$ & $\begin{array}{c}\text { Paleta de cores do } \\
\text { SPRING }\end{array}$ \\
\hline $920-940$ & Lima \\
\hline $940-960$ & Verde \\
\hline $960-980$ & Verde Escuro \\
\hline $980-1000$ & Amarelo \\
\hline $1000-1020$ & Cáqui \\
\hline $1020-1040$ & Dourado \\
\hline $1040-1060$ & Laranja Escuro \\
\hline $1060-1080$ & Chocolate \\
\hline $1080-1100$ & Dourado Escuro \\
\hline $1100-1120$ & Salmão \\
\hline $1120-1140$ & Rubro \\
\hline $1140-1160$ & Vermelho \\
\hline$>1160$ & Peru \\
\hline
\end{tabular}

QUADRO 1 - CLASSES HIPSOMÉTRICAS E CORESASSOCIADAS FONTE: Org. BINDA, 2007.

\section{c) Geração da Carta de Declividade}

Para realizar a carta de declividade, deve-se inicialmente criar um novo modelo de dados numérico (MNT), visto que o plano de informação gerado pela grade TIN (Declividade), não pode ser salvo no mesmo modelo de dados de origem. Posteriormente, deve-se utilizar a função Declividade (que é utilizada também para elaboração do mapa de exposição de vertentes), selecionando como entrada de dados a grade TIN, e escolhendo a declividade como parâmetro de saída, tão bem quanto, a unidade (porcentagem ou graus), e resolução da imagem gerada.

Após ser feita a imagem da declividade, deve-se criar um modelo de dados temático com as classes de declividade, neste caso conforme Ross (2000): 0-6\%, $6-12 \%, 12-20 \%, 20-30 \%$ e >30\%. Como variável visual estabeleceram-se cores diferenciadas, conforme o quadro a seguir (Quadro 2):

\begin{tabular}{|c|c|}
\hline $\begin{array}{c}\text { Classes de Declividades } \\
(\mathbf{\%})\end{array}$ & $\begin{array}{c}\text { Paleta de cores do } \\
\text { SPRING }\end{array}$ \\
\hline $0-6$ & Verde \\
\hline $6-12$ & Cáqui \\
\hline $12-20$ & Laranja Escuro \\
\hline $20-30$ & Urucum \\
\hline$>30$ & Marrom \\
\hline
\end{tabular}

QUADRO 2 - CLASSES DE DECLIVIDADE E CORES ASSOCIADAS FONTE: Org.: BINDA, 2007. Adaptado de Ross (2000).

O próximo passo é fatiar a imagem gerada pela função Declividade utilizando para isto da função Fatiamento definindo as fatias e associando a elas as respectivas classes de declividade.

\section{d) Geração da Carta de Exposição de Vertentes}

Para a geração da carta de exposição de vertentes, utilizou-se também da função Declividade, no entanto, deve-se selecionar a opção exposição de vertentes como parâmetro de saída. Semelhante à geração da carta de declividade, para gerar uma carta de exposição das vertentes, deve-se criar um modelo de dados temático com as seguintes classes: Norte, Sul, Leste e Oeste.

Para o fatiamento da imagem de exposição de vertentes, deve-se entrar com parâmetros apropriados. Dessa forma, definiram-se as fatias considerando uma circunferência $\left(360^{\circ}\right)$, dividida em quatro quadrantes e associadas às classes temáticas da seguinte maneira: $0-45^{\circ}$ e $315-360^{\circ}$ Norte, $45-135^{\circ}$ Leste, $135-225^{\circ}$ Sul e 225-315 Oeste (Figura 1).

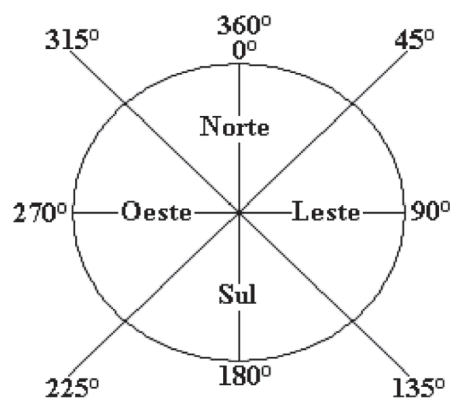

FIGURA 1 - EXPOSIÇÃO DAS VERTENTES E GRAUS DE UMA CIRCUNFERENNCIA

FONTE: Org.: BINDA, 2007. 
BINDA, L. A.; BERTOTTI, G. L. Mapeamento de características físicas do relevo da cidade de Guarapuava-PR...

e) Geração da Carta de Solos

Para a realização da carta de solos, partiu-se do mapa de coberturas inconsolidadas realizado no perímetro urbano de Guarapuava no ano de 1992 pela Minerais do Paraná S/A (MINEROPAR). Dessa forma, este mapa passou pelo processo de scanneamento, conversão no formato Grib e georreferenciamento. Uma vez georreferenciado todas as informações foram digitalizadas de modo a criar polígonos que então seriam atribuídos às respectivas classes temáticas.

Para realizar as atualizações, utilizou-se da classificação de solos, considerando principalmente as características do relevo, que segundo Vieira (1988, p. 66) pode influenciar decisivamente na formação do solo, principalmente em relação à sua profundidade, pois "os solos formados nas partes altas (eluviais) diferem dos das encostas (coluviais) e esses, por sua vez, dos das baixadas" (aluviais).

\section{f) Geração da Carta de Formas do Relevo}

O mapeamento geomorfológico da área de estudo, compreende $05^{\circ}$ Táxon da cartografação e análise geomorfológica de Ross $(2000,2003)$. Refere-se a escalas de detalhe como 1:25.000, 1:10.000 e 1.5.000. Os elementos cartografados referem-se às formas de relevo, mais especificamente as formas das encostas, a Figura 2, apresenta em síntese os táxons propostos por Ross $(2000,2003)$.

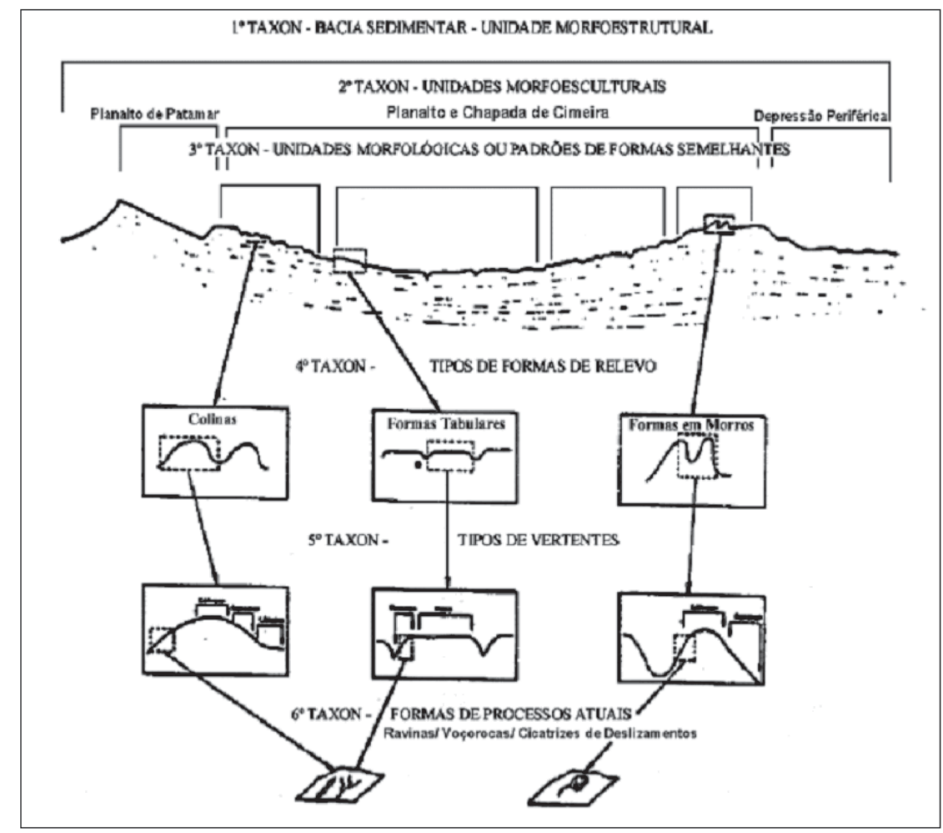

FIGURA 2 - TÁXONS DE CARTOGRAFAÇÃO E ANÁLISE GEOMORFOLÓGICA. FONTE: Ross (1992 $2^{4}$ apud SPÖRL, 2001).

Para a realização da carta de formas do relevo, utilizou-se do mapa topográfico (curvas de nível com eqüidistância de $5 \mathrm{~m}$ ) e interpretação de fotos aéreas do perímetro urbano de Guarapuava do ano de 1996. A metodologia utilizada para a confecção da carta de formas do relevo foi adaptada dos trabalhos realizados por Nunes (2002; 2005) e Nunes et al. (2006a; 2006b), em que foram definidos três compartimentos de relevo, quais sejam: 1) Planície aluvial ou fundo de vale e várzeas, 2) Domínio das vertentes côncavo-convexas ou mistas e 3) Topo suavemente ondulado das colinas convexizadas. As feições ou formas das encostas foram classificadas em côncavas, convexas e retilíneas, no entanto, acredita-se que além da classificação das formas em perfil, uma boa carta de formas do relevo, deve-se também conter a visão em planta do terreno. Dessa forma, utilizou-se das considerações realizadas por Parsons (1988 ${ }^{5}$ apud GUERRA, 2007), o qual descreve nove tipos de combinações, considerando as formas côncavas, convexas e retilíneas, em perfil e em planta, conforme mostra a Figura 3.

4 ROSS, J.L.S. O registro cartográfico dos fatos geomórficos e a questão da taxonomia do relevo. Revista do Departamento de Geografia. n. 6. São Paulo,1992.

5 PARSONS, A.J. Hillslope form. Routledge, New York, Estados Unidos, 1988. 


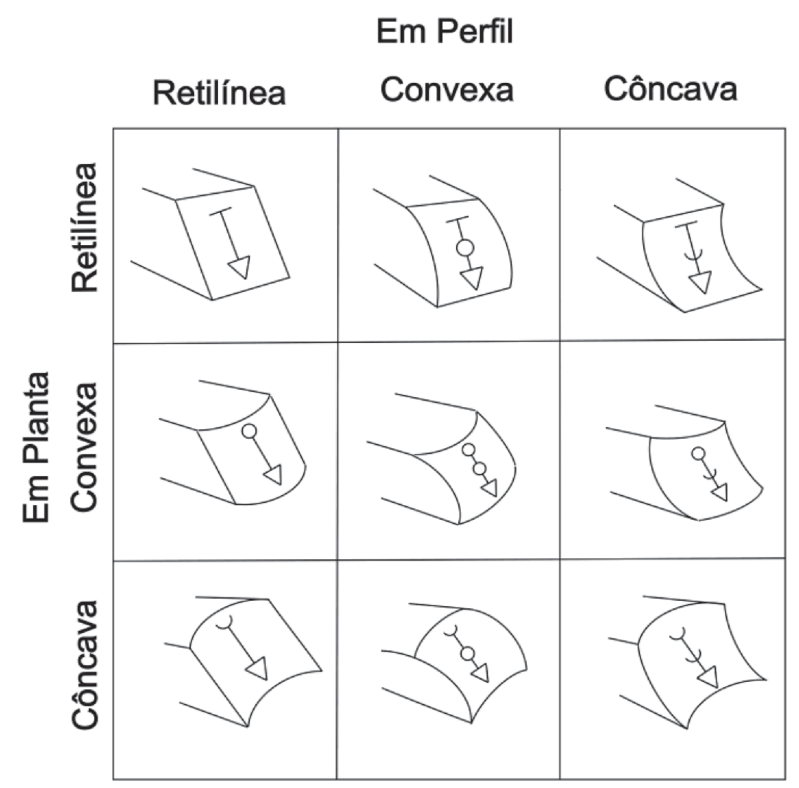

FIGURA 3 - COMBINAÇÕES DAS FORMAS DAS ENCOSTAS E SIMBOLOGIA

FONTE: Parson (1988 apud GUERRA, 2007, p.194) modificado.

As demais informações contidas na carta das formas de relevo estão relacionadas à demarcação das linhas de divisores d'água dos topos suavemente convexizados e rupturas de declive.

A simbologia utilizada na carta de formas de relevo foi elaborada no software Autodesk Map versão 2002, sendo a mesma salva no formato Drawing Exchange Format - DXF-R12 e acrescentada na pasta de arquivos de símbolos do software SPRING. A edição da carta e suas atribuições de classes temáticas foram realizadas no software SPRING, no entanto, optou-se por acrescentar as simbologias de formas de relevo no módulo
SCARTA, na etapa de realização do layout da carta.

\section{LOCALIZAÇÃO E CARACTERÍSTICAS GERAIS DO MUNICÍPIO DE GUARAPUAVA}

O Município de Guarapuava localiza-se na região centro-sul do Estado do Paraná (Figura 4), no terceiro planalto paranaense ou planalto de Guarapuava (MAACK, 2002). Apresenta uma população total de 155.161 habitantes, distribuídos em 141.694 na área urbana (91,3\%), e apenas 13.467 na área rural (8,7\%) (IBGE, 2000).

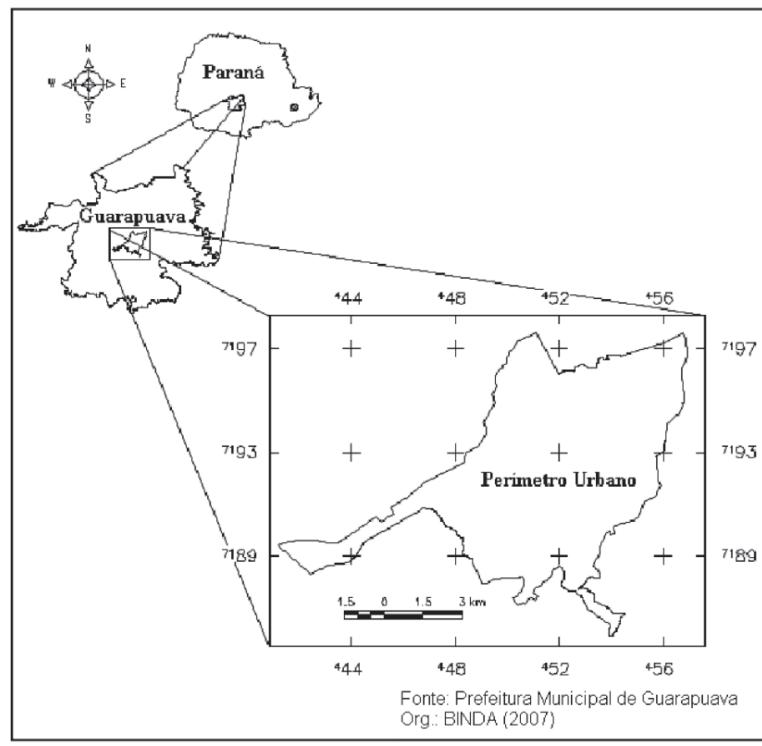

FIGURA 4 - LOCALIZAÇÃO DO MUNICÍPIO DE GUARAPUAVA-PR

FONTE: Prefeitura Municipal de Guarapuava (2003). 
BINDA, L. A.; BERTOTTI, G. L. Mapeamento de características físicas do relevo da cidade de Guarapuava-PR...

Segundo Maack (2002), Guarapuava caracterizase por uma paisagem de campo limpo, capões e matas de galeria associadas às araucárias. Em relação ao clima, o mesmo autor, classifica o Município de Guarapuava como pertencente à zona de clima quentetemperado subtropical fresco até frio no inverno. $\mathrm{Na}$ classificação de Koeppen localiza-se em Cfb, ou seja, na zona temperada sempre úmida, com mais de cinco geadas por ano (MAACK, 2002).

Thomaz e Vestena (2003) analisaram 25 anos de dados meteorológicos do Município de Guarapuava (de 1976 a 2000), e obtiveram como temperatura média anual em torno de $17^{\circ} \mathrm{C}$ e, observaram também, que a temperatura máxima ocorreu em novembro de 1985 quando chegou a $360 \mathrm{C}$. Ao contrário a temperatura mínima registrada ocorreu em junho de 1978 quando os termômetros marcaram $-6,80 \mathrm{C}$. Quanto ao volume de precipitação anual, a média do município é de 1961 mm, distribuídos numa média de 149 dias com chuva. Durante 0 ano ocorre graças à atuação da Mpa (Massa Polar Atlântica), mais intensa nos meses mais frios uma média de 13 a 15 eventos de geada no município (THOMAZ; VESTENA, 2003).

No que tange as litologias que ocorrem no Município de Guarapuava, essas se enquadram no Grupo São Bento, mais especificamente nas Formações Botucatu (arenitos eólicos) e Serra Geral (ígneas ácidas e básicas). Neste sentido, nota-se a ocorrência dos arenitos Botucatu na área leste do município com a Escarpa da Esperança. O magmatismo fissural da Formação
Serra Geral, gerou diferentes tipos de rochas, embora as rochas de natureza básica (principalmente basaltos) predominem em mais de 97,5\% desta formação, há a ocorrência de rochas de natureza ácida (principalmente riodacitos) (MELFI, et al. 1988; NARDY, et al.2002).

Nardy (1995) identificou e classificou as rochas da Formação Serra Geral em quatro unidades litoestratigráficas para a Região Central da Bacia do Paraná, destas, três são identificadas no município de Guarapuava. A área urbana do município compõe-se quase que exclusivamente por riodacitos do Tipo Chapecó, sobrepostos aos basaltos da Unidade JKSGB1 ou Unidade Básica Inferior, estes que ocorrem em uma faixa ao longo da margem direita do Rio Cascavel e a sudeste formando a Escarpa do Rio Jordão. A Unidade JKSGB2 ou Unidade Básica Superior ocorre numa faixa que passa pelo Distrito da Palmeirinha, e expande-se em direção sudoeste, mostrando sua feição característica (fraturamento cerrado) (MINEROPAR, 1992; NARDY, 1995).

\section{APRESENTAÇÃO E DISCUSSÃO DOS DOCUMEN- TOS CARTOGRÁFICOS}

a) Carta de Hidrografia e Bacias Hidrográficas Urbana Com a Carta de hidrografia e bacias hidrográficas urbanas (Carta 1), utilizou-se a função Medidas e classes do software SPRING, os resultados são apresentados nos Quadros 3 e 4.

\begin{tabular}{|l|c|c|l|}
\hline \multicolumn{1}{|c|}{ Classes } & Comprimento $\mathbf{( k m )}$ & $\ldots$ & \\
\hline Rios intermitentes & 19,678 & - & Comprimento Total de \\
Rios perenes & 86,754 & - & canais: $106,433 \mathrm{~km}$ \\
\hline Lagos e Lagoas & 26,765 & 0,340 & Área total de terrenos \\
\hline Várzea & 57,096 & 1,786 & alagadiços: $2,126 \mathrm{~km}^{2}$ \\
\hline
\end{tabular}

QUADRO 3 - COMPRIMENTO E ÁREA DA HIDROGRAFIA DO PERÍMETRO URBANO DE GUARAPUAVA

FONTE: Medidas de classes (SPRING). Org.: BINDA, 2007.

Como pode ser visto no Quadro 3, o perímetro urbano de Guarapuava apresenta aproximadamente $86,754 \mathrm{~km}$ de rios perenes. Somando a esses os rios intermitentes, obtêm-se 106,433 km, valor que representa o comprimento total dos canais no ambiente urbano. Com este dado é possível saber a densidade de drenagem no perímetro urbano de Guarapuava conforme a seguinte fórmula: $\mathrm{Dd}=\mathrm{Lt} / \mathrm{A}$, em que $\mathrm{Dd}$ é a densidade de drenagem, Lt é o comprimento total dos canais e A é área amostrada. Como resultado obteve-se o valor de $1,568 \mathrm{~km} / \mathrm{km}^{2}$, valor que indica a extensão da drenagem em $1 \mathrm{~km}^{2}$, ou seja, em $1 \mathrm{~km}^{2}$ há 1,568 km de canais fluviais (CHRISTOFOLETTI, 1980). Lagos e Lagoas representam uma área de apenas $0,340 \mathrm{~km}^{2}$ e as várzeas representam $1,786 \mathrm{~km}^{2}$, sendo que juntas perfazem um total de 2,126 km² de terrenos alagadiços. 
BINDA, L. A.; BERTOTTI, G. L. Mapeamento de características físicas do relevo da cidade de Guarapuava-PR...

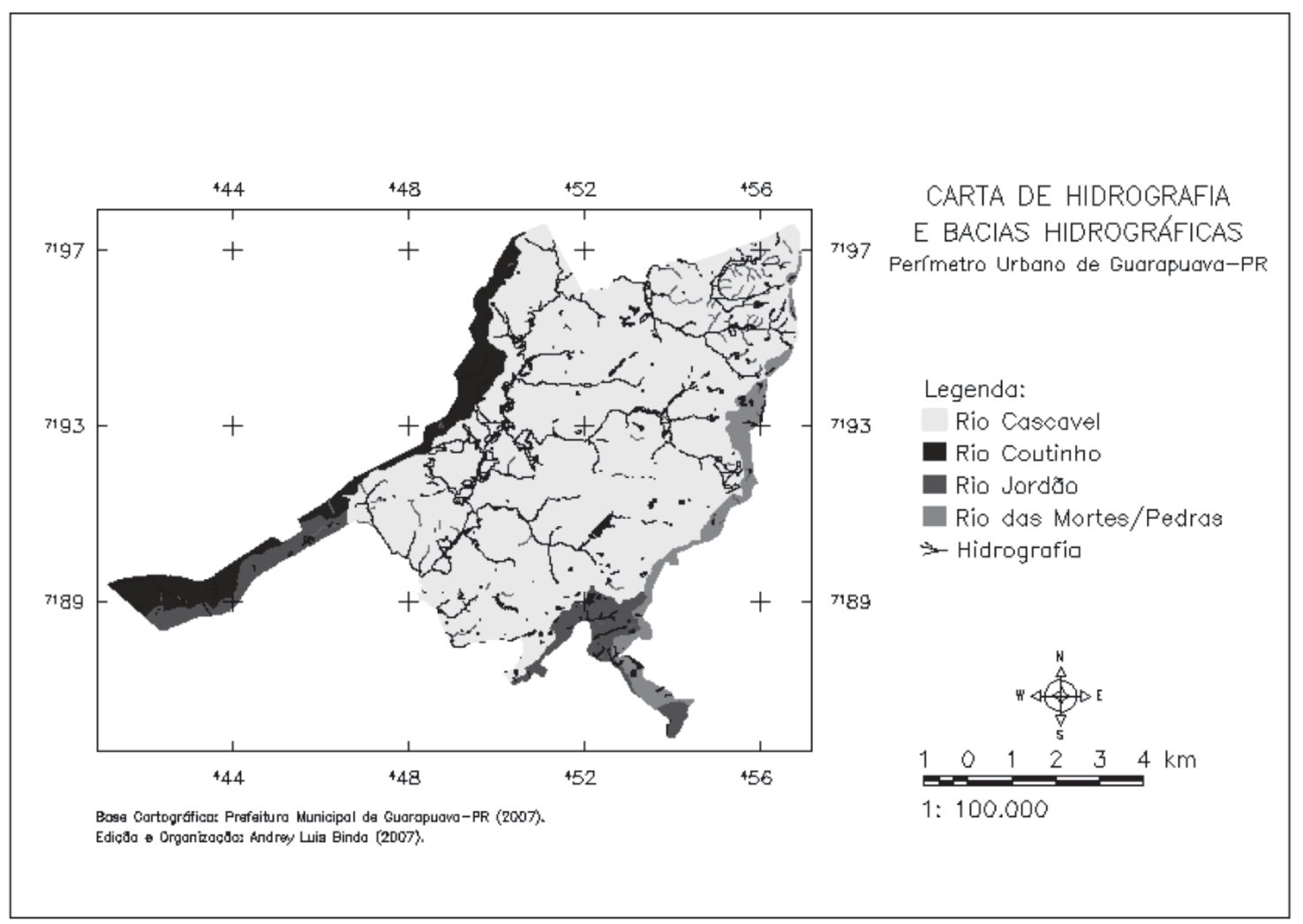

Carta 1 - Hidrografia e Bacias Hidrográficas.

No que tange às bacias hidrográficas urbana, o Quadro 4 mostra os resultados apresentados no relatório de medidas de classes do SPRING. A maior bacia hidrográfica urbana de Guarapuava é a do Rio Cascavel, que abrange $81,82 \%$ da área total. O Rio Cascavel corta o perímetro urbano de Guarapuava no sentido nordeste-sudoeste, no entanto, seus afluentes: Arroio Carro Quebrado, Arroio Barro Preto e Arroio do Engenho drenam o perímetro urbano no sentido LesteOeste, fato que demonstra um padrão de drenagem controlado pelo padrão estrutural do substrato rochoso (MINEROPAR, 1992).

\begin{tabular}{|l|c|c|}
\hline \multicolumn{1}{|c|}{ Bacias } & $\begin{array}{c}\text { Área Total } \\
\left(\mathbf{k m}^{\mathbf{2}}\right)\end{array}$ & $\mathbf{\%}$ \\
\hline Rio Cascavel & 55,520 & 81,82 \\
\hline Rio Coutinho & 5,129 & 7,56 \\
\hline Rio Jordão & 4,231 & 6,23 \\
\hline Rio das Mortes/Pedras & 2,978 & 4,39 \\
\hline Total & $\mathbf{6 7 , 8 5 8}$ & $\mathbf{1 0 0}$ \\
\hline
\end{tabular}

QUADRO 4 - BACIAS HIDROGRÁFICAS DO PERÍMETRO URBANO DE GUARAPUAVA

FONTE: Medidas de classes (SPRING). Org.: BINDA, 2007.

A Bacia do Rio Coutinho representa apenas $7,56 \%$ do perímetro urbano de Guarapuava, ocorre como uma faixa que se estende de nordeste para leste (braço do perímetro). A Bacia do Rio Jordão 6 ocorre em

6 Embora todas as bacias hidrográficas façam parte da Bacia do Rio Jordão, considerou-se como Bacia Hidrográfica do Rio Jordão, apenas as porções drenadas pelo rio propriamente dito. 
BINDA, L. A.; BERTOTTI, G. L. Mapeamento de características físicas do relevo da cidade de Guarapuava-PR...

$6,23 \%$ da área do perímetro urbano, ocorre na porção sul do bairro Boqueirão, Vila Jordão e na faixa nordestesudoeste do braço do perímetro. Já a Bacia do Rio das Mortes/Pedras, ocorre em apenas 4,39\% da área do perímetro urbano de Guarapuava e ocorre margeando a escarpa do Jordão (Serra do Jordão) numa faixa que estende do extremo leste ao extremo sul do perímetro urbano.

\section{b) Carta de Hipsometria}

O perímetro urbano de Guarapuava está inserido em altitudes que se situam entre 920 m (trecho próximo à foz do Rio Cascavel) e 1164,51m (extremo oeste), dessa forma, pode-se estimar a amplitude altimétrica em aproximadamente $244,51 \mathrm{~m}$.

No entanto, cerca de 55\% da área total do períme- tro urbano está situada em altitudes entre 1020 e 1080 m. Essas ocorrem em ambos os lados do Rio Cascavel e no divisor d'águas entre as bacias hidrográficas dos rios Jordão e Coutinho. Altitudes superiores (1080-1164,51 $\mathrm{m}$ ) ocorrem em aproximadamente $30 \%$, principalmente no extremo oeste do perímetro urbano, limitada pelo lineamento (NE-SW) da falha do Rio das Pedras. As altitudes inferiores (920-1020) estão restritas a 15\% da área total do perímetro, e encontram-se situadas junto a planície aluvial do Rio Cascavel, embora ocorra na Vila Jordão após a ruptura de declive da falha do Rio das Pedras.

A carta de hipsometria (Carta 2) é dividida em 13 classes conforme apresenta o Quadro 5, o qual também traz a área e a porcentagem de cada classes em relação ao perímetro urbano de Guarapuava.

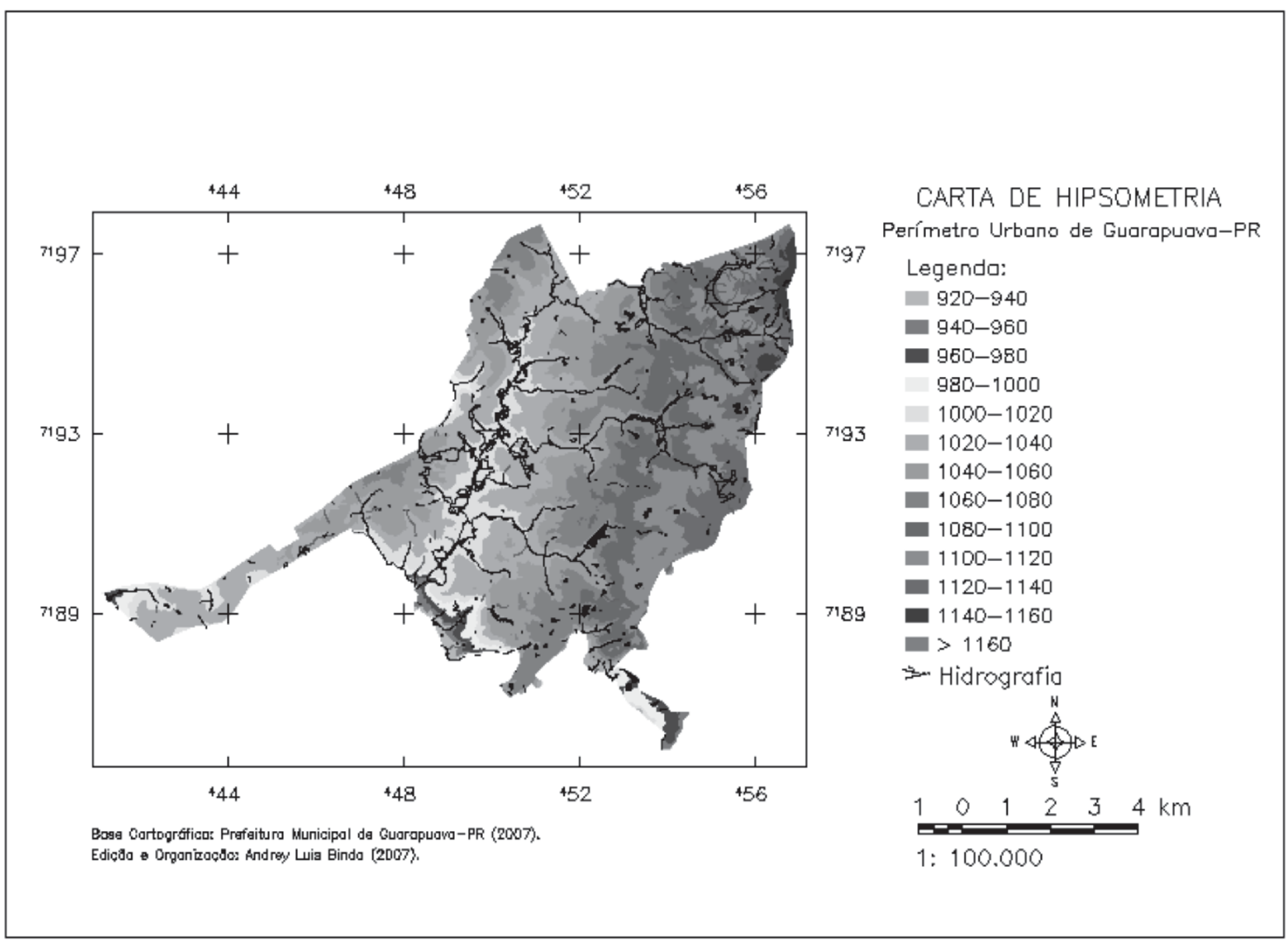

Carta 2 - Hipsometria 


\begin{tabular}{|c|c|c|}
\hline $\begin{array}{c}\text { Classes } \\
(\mathbf{m})\end{array}$ & Área $\left.\mathbf{( k m}^{\mathbf{2}}\right)$ & $\%$ \\
\hline $920-940$ & 0,283 & 0,41 \\
\hline $940-960$ & 0,434 & 0,64 \\
\hline $960-980$ & 0,924 & 1,36 \\
\hline $980-1000$ & 1,493 & 2,20 \\
\hline $1000-1020$ & 7,055 & 10,39 \\
\hline $1020-1040$ & 14,935 & 22,01 \\
\hline $1040-1060$ & 12,658 & 18,65 \\
\hline $1060-1080$ & 9,885 & 14,57 \\
\hline $1080-1100$ & 7,574 & 11,16 \\
\hline $1100-1120$ & 7,666 & 11,29 \\
\hline $1120-1140$ & 4,287 & 6,32 \\
\hline $1140-1160$ & 0,662 & 0,97 \\
\hline$>1160$ & 0,002 & 0,03 \\
\hline Total & $\mathbf{6 7 , 8 5 8}$ & $\mathbf{1 0 0}$ \\
\hline
\end{tabular}

QUADRO 5 - ÁREA TOTAL POR CLASSES DE HIPSOMETRIA

FONTE: Medidas de classes (SPRING). Org.: BINDA, 2007.

c) Carta de Declividade

A carta de declividade (Carta 3) foi elaborada considerando os parâmetros instituídos por Ross (2000).
Dessa forma, para cada classe de declividade o referido autor atribuiu uma respectiva categoria de fragilidade ambiental, conforme mostra o Quadro 6.

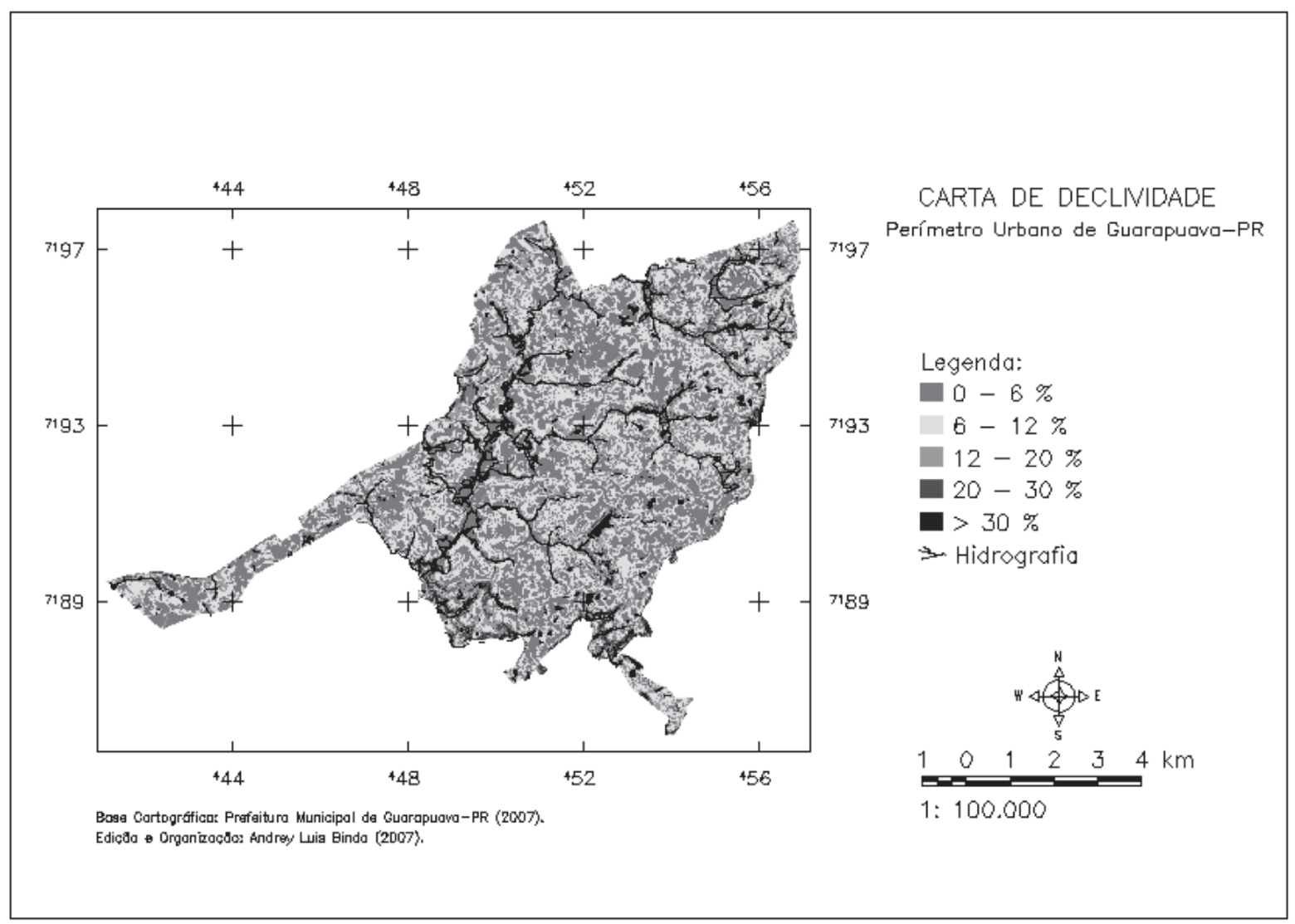

Carta 3 - Declividade 
BINDA, L. A.; BERTOTTI, G. L. Mapeamento de características físicas do relevo da cidade de Guarapuava-PR...

\begin{tabular}{|c|c|}
\hline$\%$ & Categorias \\
\hline $0-6$ & Muito Fraca \\
\hline $6-12$ & Fraca \\
\hline $12-20$ & Média \\
\hline $20-30$ & Forte \\
\hline$>30$ & Muito Forte \\
\hline
\end{tabular}

QUADRO 6 - CLASSES DE DECLIVIDADE E CATEGORIAS DE FRAGILIDADE AMBIENTAL FONTE: Ross (2000). Org. Binda (2007).

O perímetro urbano de Guarapuava apresenta aproximadamente $80 \%$ de sua área em áreas com declividades que se situam entre 0 a $12 \%$ estas consideradas de muito fraca a fraca fragilidade ambiental. Ocorrem preferencialmente nos topos suavemente convexizados e nas planícies de inundação dos rios, sobretudo, do Rio Cascavel.

Pouco mais de $15 \%$ do perímetro urbano encontra-se em áreas entre 12 a 20\%, ou seja, em área com média fragilidade ambiental. As áreas de fragilidade ambiental de forte a muito forte, ou seja, superior a $20 \%$ encontram-se em locais mais dissecados do relevo, ocorrendo principalmente nos setores próximos à ruptura de declive do Rio das Pedras e do Rio Cascavel. Digno de nota é o fato de o bairro Olarias apresentar aproximadamente $25 \%$ de sua área em condições de forte a muito forte grau de fragilidade ambiental (>20\%). Outros setores do perímetro urbano merecem atenção redobrada, principalmente, na implantação de novos loteamentos, esses locais encontram-se no extremo sul do bairro Boqueirão, no oeste do bairro Morro Alto e também próximo ao seu limite com o bairro São Cristóvão, no setor sudoeste do Imóvel Morro Alto e porção sul do bairro Alto Cascavel. O Quadro 7, mostra as classes temáticas e suas respectivas áreas e porcentagem do perímetro urbano.

\begin{tabular}{|l|c|c|}
\hline Classes $\mathbf{( \% )}$ & Área $\mathbf{( k m}^{\mathbf{2}}$ ) & $\mathbf{\%}$ \\
\hline $0-6$ & 27,667 & 40,77 \\
\hline $6-12$ & 26,161 & 38,55 \\
\hline $12-20$ & 10,415 & 15,35 \\
\hline $20-30$ & 2,300 & 3,39 \\
\hline$>30$ & 1,315 & 1,94 \\
\hline Total & $\mathbf{6 7 , 8 5 8}$ & $\mathbf{1 0 0}$ \\
\hline
\end{tabular}

QUADRO 7 - ÁREA TOTAL POR CLASSE DE DECLIVIDADE FONTE: Medidas de classes (SPRING). Org.: BINDA, 2007

d) Carta de Exposição de Vertentes

A carta de exposição de vertentes (Carta 4) apresenta a orientação das encostas em relação aos pontos cardeais. Neste trabalho consideraram-se apenas quatro orientações, quais sejam: Norte, Sul, Leste e Oeste.

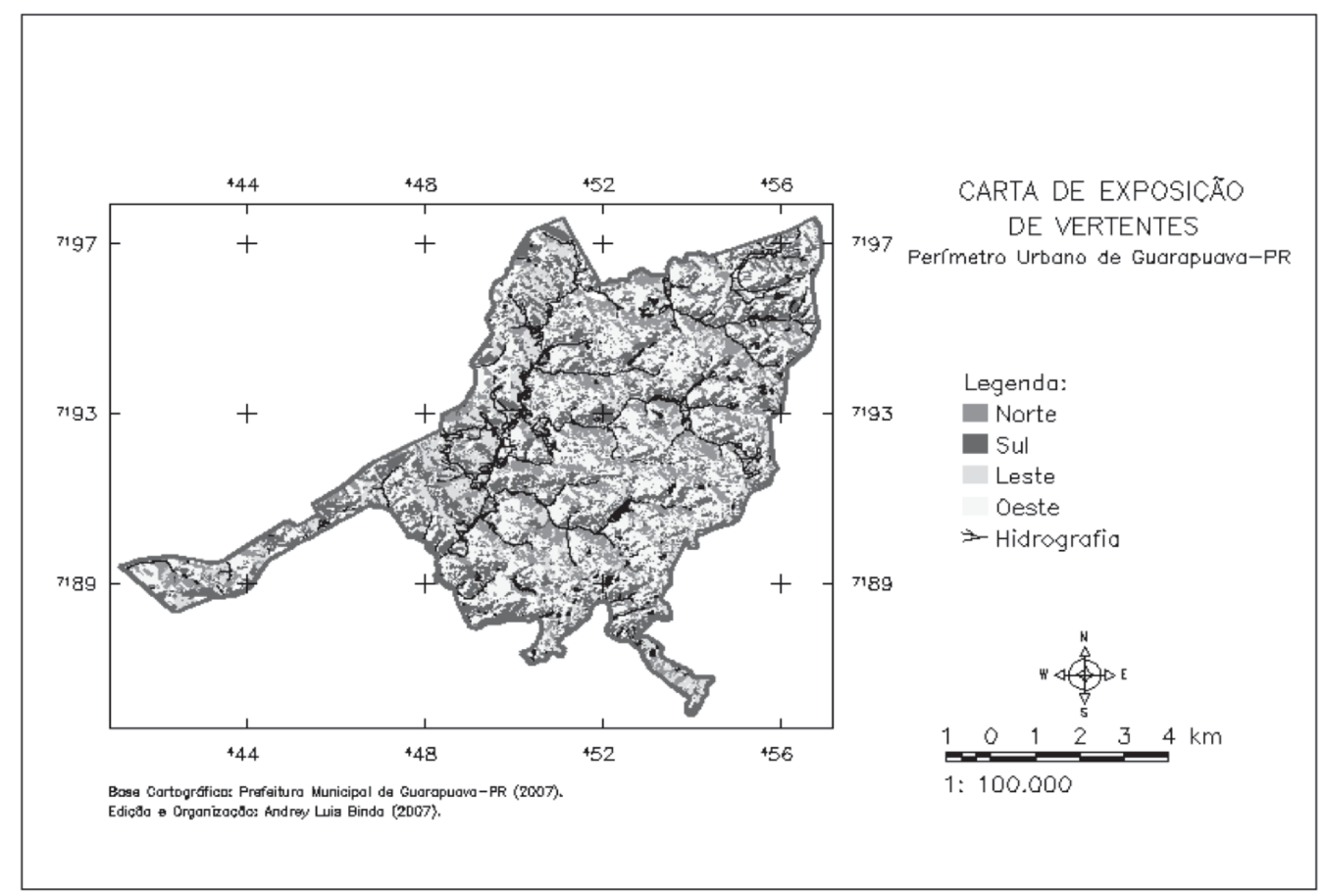

Carta 4 - Exposição de Vertentes 
No perímetro urbano de Guarapuava, há uma predominância das encostas com exposição para oeste, as quais ocupam cerca de $30,52 \%$ da área. Isso se deve à assimetria dos divisores d'água da bacia do Rio Cascavel que tem encostas mais desenvolvidas na margem esquerda, ao passo que as encostas com orientações para leste restringem-se a $14,80 \%$ da área urbana de Guarapuava. Já as orientações norte e sul apresentam valores muito próximos, $24,35 \%$ e $22,61 \%$ da área respectivamente. Áreas planas restringem-se a 7,75\% da área total do perímetro urbano. O Quadro 8 apresenta esses valores.

\begin{tabular}{|l|c|c|}
\hline Exposição & Área $\mathbf{( k m}^{\mathbf{2}} \mathbf{)}$ & $\mathbf{\%}$ \\
\hline Norte & 16,508 & 24,32 \\
\hline Sul & 15,346 & 22,61 \\
\hline Oeste & 20,712 & 30,52 \\
\hline Leste & 10,049 & 14,80 \\
\hline Áreas planas & 5,243 & 7,75 \\
\hline Total & $\mathbf{6 7 , 8 5 8}$ & $\mathbf{1 0 0}$ \\
\hline
\end{tabular}

QUADRO 8 - EXPOSIÇÃO DAS VERTENTES

FONTE: Medidas de classes (SPRING). Org.: BINDA, 2007

e) Carta de Solos

A Carta de Solos (Carta 5) foi elaborada segundo as classes temáticas (classes de solos) instituídas pela MINEROPAR. Assim, os solos do perímetro urbano de Guarapuava, podem ser divididos em três, conforme a MINEROPAR (1992): Solos orgânicos (Organossolos), Latossolos e Litossolos (Neossolos litólicos). O Quadro 9 indica os seguintes resultados em área de abrangência.

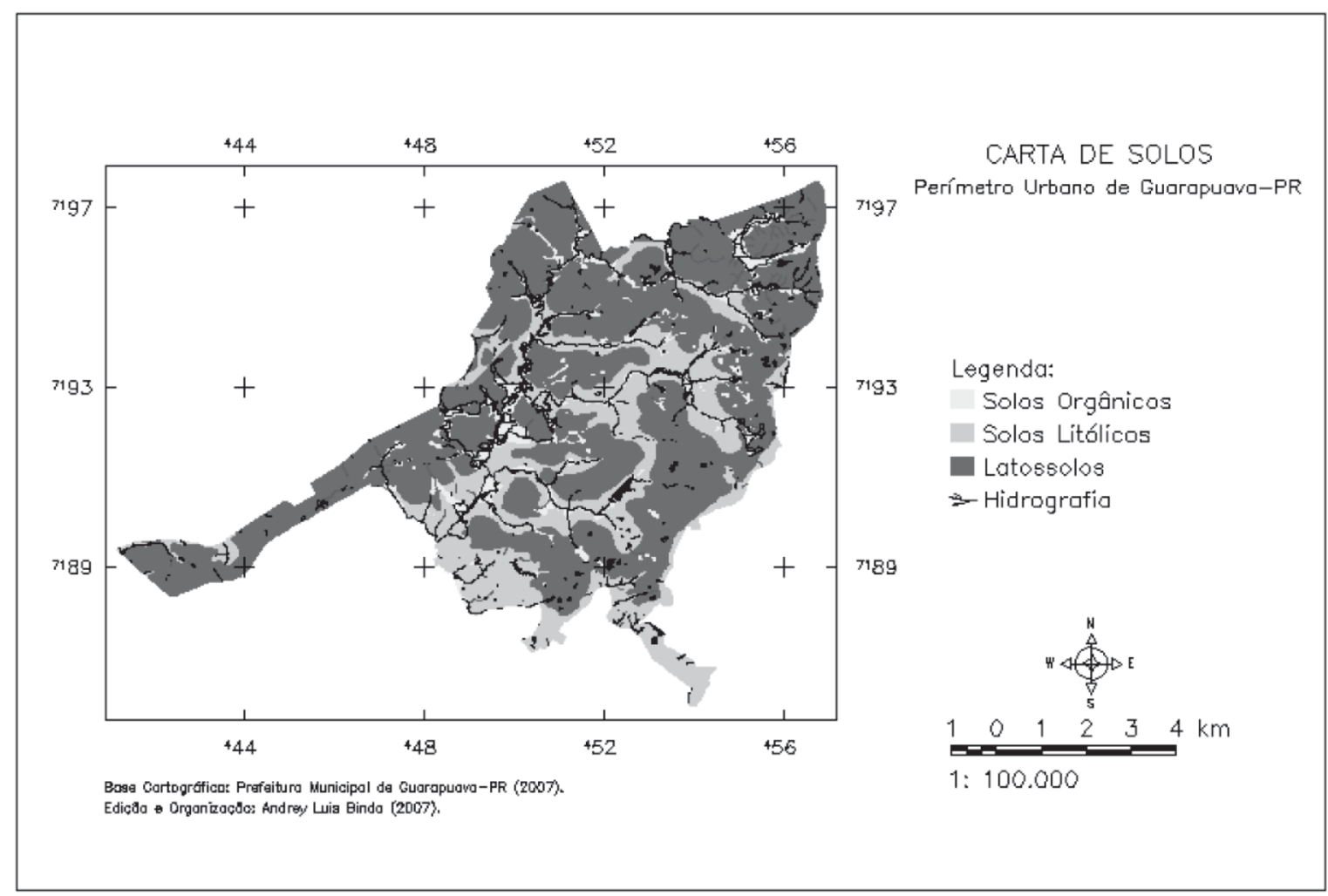

Carta 5 - Solos 
BINDA, L. A.; BERTOTTI, G. L. Mapeamento de características físicas do relevo da cidade de Guarapuava-PR...

\begin{tabular}{|l|c|c|}
\hline $\begin{array}{c}\text { Classes de } \\
\text { solos }\end{array}$ & Área $\left.\mathbf{( k m}^{2}\right)$ & $\mathbf{\%}$ \\
\hline Orgânicos & 6,812 & 10,04 \\
\hline Litólicos & 18,915 & 27,87 \\
\hline Latossolos & 42,131 & 62,09 \\
\hline Total & $\mathbf{6 7 , 8 5 8}$ & $\mathbf{1 0 0}$ \\
\hline
\end{tabular}

QUADRO 9 - ÁREA TOTAL POR CLASSE DE SOLO

FONTE: Medidas de classes (SPRING). Org.: BINDA, 2007.

Os solos orgânicos (Organossolos) compreendem solos hidromórficos (ambientes aquosos), essencialmente orgânicos e de coloração escura, que tem sua gênese em condições de má drenagem, com lençol freático próximo ou aflorando à superfície (MINEROPAR, 1992). Ocorrem em aproximadamente $10,03 \%$ do perímetro urbano e estão relacionados principalmente com áreas de baixada e próximo aos canais fluviais. Segundo a MINEROPAR (1992) em Guarapuava esses solos assentam diretamente sobre o substrato rochoso e apresentam espessura que varia de 0,5 a 3,00 $\mathrm{m}$, podendo em alguns locais apresentar espessuras superiores a estas.

Os latossolos são solos minerais, com boa drenagem e a presença de um horizonte $A$ proeminente e um horizonte $B$ latossólico, a transição do horizonte A para o B é normalmente gradual, possui coloração avermelhada, castanho-avermelhada ou vermelhoescura. No perímetro urbano de Guarapuava, cobrem aproximadamente $62,08 \%$ da área total, ocorrem predominantemente nas áreas mais planas, nos topos de das vertentes com relevo suave, sua espessura varia entre 1,00 a 6,00 m (MINEROPAR, 1992).

Já os litossolos correspondem aos solos pouco evoluídos, ocorrem em aproximadamente $27,87 \%$ do perímetro urbano de Guarapuava e estão relacionados às áreas com maiores declives (>20\%), embora possam ser encontrados em porções mais planas. Sua espessura é da ordem de 0,20 a 1,00 m (MINEROPAR, 1992).

\section{f) Carta de Formas de Relevo}

A metodologia utilizada para a elaboração da carta de formas de relevo (Carta 6) foi a de Nunes (2002) e Nunes et al. (2005; 2006a; 2006b) em que os compartimentos de relevo do são divididos em: 1) Planície aluvial ou fundo de vale e várzeas, 2) Domínio das vertentes côncavo-convexas-retilíneas ou mistas e 3) Topo suavemente ondulado das colinas convexizadas.

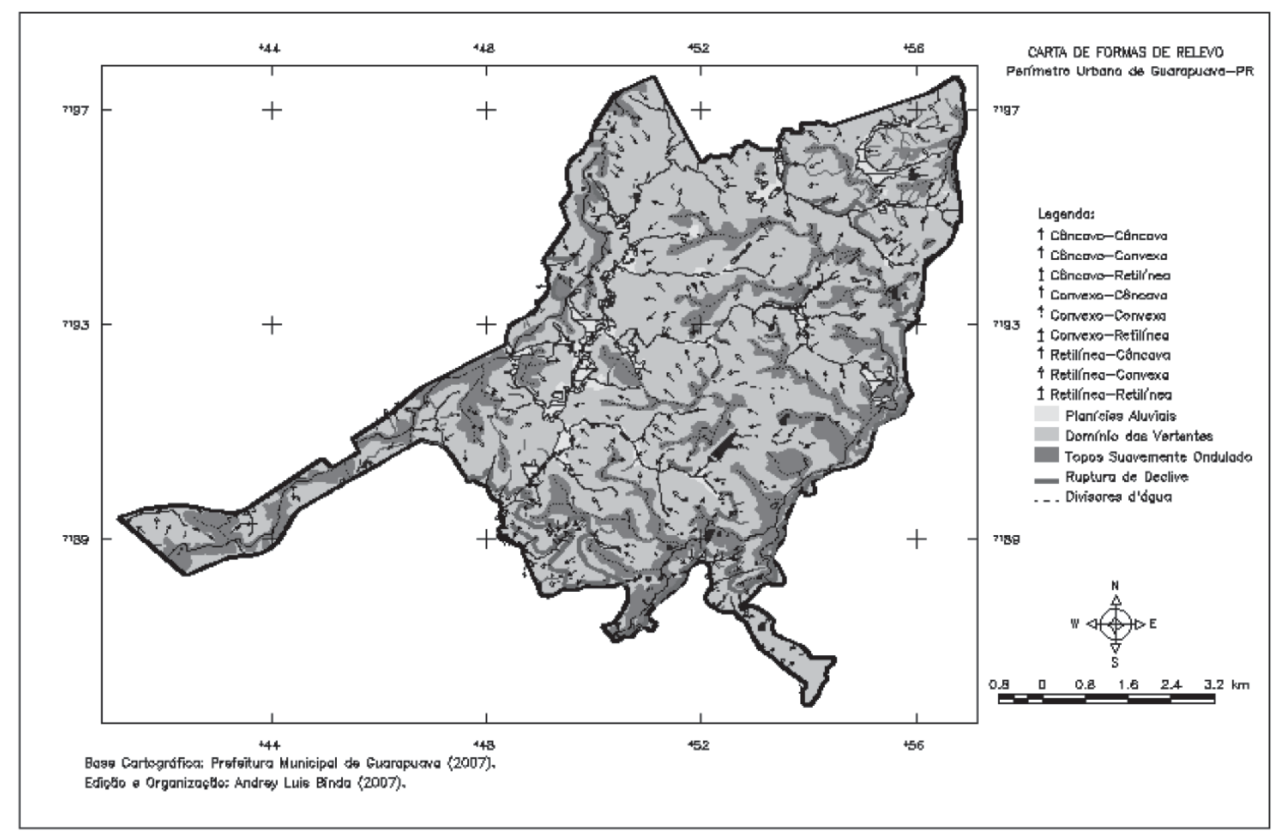

Carta 6 - Formas de relevo 
BINDA, L. A.; BERTOTTI, G. L. Mapeamento de características físicas do relevo da cidade de Guarapuava-PR...

Dessa forma, pôde-se perceber que as áreas de topo suavemente ondulado das colinas convexizadas, abragem cerca de $20,70 \%$, as planícies aluviais restringem-se a 5,74\% e o domínio das vertentes côncavoconvexas-retilíneas ocorre em $73,56 \%$ da área total do perímetro urbano de Guarapuava. Essas informações estão listadas no Quadro 10.

\begin{tabular}{|l|c|c|}
\hline Compartimentos do relevo & Área $\left(\mathbf{k m}^{2}\right)$ & $\%$ da área \\
\hline Planícies Aluviais & 3,893 & 5,74 \\
\hline Topo Suavemente Ondulado & 14,046 & 20,70 \\
\hline Domínio das Vertentes & 49,919 & 73,56 \\
\hline Total & $\mathbf{6 7 , 8 5 8}$ & $\mathbf{1 0 0}$ \\
\hline
\end{tabular}

QUADRO 10 - ÁREA TOTAL POR COMPARTIMENTO DE RELEVO

FONTE: Medidas de classes (SPRING). Org.: BINDA, 2007.

No que tange às formas das encostas em perfil, essas são predominantemente convexas e côncavas, com apenas alguns esparsos segmentos retilíneos. Quanto à visão em planta, são predominantes as formas convexas e côncavas (cabeceiras de drenagem).

Segundo Guerra (2007) é de suma importância o mapeamento das formas das encostas, pois aquelas de formas convexas se caracterizam pela divergência de fluxo e assim sujeitas a processos de erosão e movimentos de massa. Já as formas côncavas estão relacionadas à convergência de fluxos d'água, estando associadas tanto à deposição quanto à erosão.

Partindo desse pressuposto, a carta de formas do relevo, pode ser utilizada no planejamento urbano, principalmente, na instalação de rede de drenagem de águas pluviais, pois esses projetos poderiam estar utilizando justamente daqueles locais em que naturalmente há a concentração de água (áreas côncavas em perfil e em planta).

\section{CONSIDERAÇÕES FINAIS}

O conhecimento da realidade dos aspectos físicos de determinada região é de suma importância para se pensar a relação sociedade-natureza. No entanto, o que se tem visto nas últimas décadas é a aplicabilidade do conhecimento científico, com vistas apenas à quantificação dos recursos passíveis de serem aproveitados pela sociedade capitalista.

Muitos dos problemas ambientais decorrentes da má utilização dos bens naturais são resultantes, do desconhecimento da aptidão e dos limites impostos pela natureza. A produção do espaço urbano leva a significativas alterações no quadro natural de uma região, dessa forma, conhecer melhor estas limitações e aptidões de uma área, faz-se extremamente necessário, para uma ocupação mais racional respeitando as limitações impostas pelos aspectos físicos.

Com isso, estudos dessa natureza fornecem uma importante fonte de dados que podem (e devem) ser aplicado no planejamento urbano, principalmente, nas leis de uso e ocupação do solo urbano. Xavier da Silva (1995) chama atenção especial ao papel da geomorfologia como geradora de informações importantes para o planejamento territorial e, sobretudo, pela utilização do geoprocessamento como ferramenta de investigação de fatos geomorfológicos.

Porém, a ocupação do espaço urbano não se restringe aos fatores ambientais, mas também aos econômicos, sociais, culturais e políticos (MARÇAL; GUERRA, 2006) fatores esses que podem ser levantados em pesquisas futuras.

\section{REFERÊNCIAS}

BRASIL. Fundação Instituto Brasileiro de Geografia e Estatística - IBGE. Censo Demográfico 2000. Disponível em: <http:// ibge.gov.br/home/estatistica/populacao/censo2000/universo. php?tipo=31\&paginaatual $=1 \& u f=41 \&$ letra $=G>$. Acesso em: 26/3/2007.

CHRISTOFOLETTI, A. Geomorfologia. 2. ed. São Paulo: Edgard Blucher, 1980.

GUERRA, A. J. T.; MARÇAL, M. S. Geomorfologia ambiental. Rio de Janeiro: Bertrand Brasil, 2006.

GUERRA, A. J. T. Encostas e a questão ambiental. In: CUNHA, S. B. e GUERRA, A. J. T. A questão ambiental: diferentes abordagens. 3. ed. Rio de Janeiro: Bertrand Brasil, 2007.

MAACK, R. Geografia física do Estado do Paraná. 3. ed. Curitiba: Imprensa Oficial, 2002.

MELFI. A. J.; MELFI. A. J.; PICCIRILLO, E. M.; NARDY, A. J. R. Geological and magmatic aspects of the Paraná Basin - an introduction. In: PICCIRILLO, E. M.; MELFI, A. J. (Orgs). The mesozoic flood volcanism of the Paraná Basin. São Paulo: USP - Instituto Astronômico e Geofísico, 1988.

MINEROPAR, Minerais do Paraná. Geologia de planejamento: Caracterização do Meio Físico da Área Urbana de Guarapuava. Curitiba: MINEROPAR, 1992.

NARDY, A. J. R. Geologia e petrologia do vulcanismo mesozóico da Região Central da Bacia do Paraná. Tese (Doutorado) - IGCE-UNESP, Rio Claro, 1995.

NARDY, A. J. R.; OLIVEIRA, M. A. F.; MACHADO, F. B. Geologia e Estratigrafia da Formação Serra Geral. Geociências. 
BINDA, L. A.; BERTOTTI, G. L. Mapeamento de características físicas do relevo da cidade de Guarapuava-PR...

v. 21. n. 1/2. São Paulo: UNESP, 2002.

NUNES, J. O. R. Uma contribuição metodológica ao estudo da dinâmica da paisagem aplicada à escolha de áreas para a construção de aterro sanitário em Presidente PrudenteSP. Tese (Doutorado) - UNESP/FCT, Presidente Prudente, 2002.

NUNES, J. O. R.; SAMIZAVA, T. M.; KAIDA, R. H. Estudo da dinâmica da paisagem em uma área do município de Presidente Prudente-SP: Uma proposta de zoneamento ambiental urbano. In: SIMPOSIO DE GEOGRAFIA FISICA APLICADA, 11. Anais... São Paulo: Departamento de Geografia/FFLCH/ USP, 2005.

NUNES, J. O. R; FREIRE, R.; PEREZ, I. U. Mapeamento geomorfológico do perímetro urbano do município de Presidente Prudente-SP. In: VI SIMPOSIO NACIONAL DE GEOMORFOLOGIA / REGIONAL CONFERENCE ON GEOMORPHOLOGY. Goiânia: UFG, 2006a.

NUNES, J. O. R.; IMAI, N. N.; MARTINS, E. S.; SAMIZAVA, T. M.; KAIDA, R. H. A importância do conhecimento geomorfológico na análise espacial: escolha de áreas para a construção de aterro sanitário no município de Presidente Prudente-SP. In: VI SIMPÓSIO NACIONAL DE GEOMORFOLOGIA/ REGIONAL CONFERENCE ON GEOMORPHLOGY. Goiânia: UFG, 2006b.
ROSS, J. L. S. Geomorfologia Aplicada aos EIAs-RIMAs. In: GUERRA, A. J. T.; CUNHA, S. B. (Orgs). Geomorfologia e meio ambiente. 3. ed. Rio de Janeiro: Bertrand Brasil, 2000.

ROSS, J.S.L. Geomorfologia ambiental. In: CUNHA, S. B.; GUERRA, A. J. T. Geomorfologia do Brasil. 3. ed. Rio de Janeiro: Bertrand Brasil, 2003.

SILVA, J. X. da. Geomorfologia e geoprocessamento. In: GUERRA, A. J. T.; CUNHA, S. B. Geomorfologia uma atualização de bases e conceitos. 2. ed. Rio de Janeiro: Bertrand Brasil, 1995.

SPÖRL, C. Análise da fragilidade ambiental relevo-solo com aplicação de três modelos alternativos nas altas bacias do Rio Jaguari-Mirim, Ribeirão do Quartel e Ribeirão da Prata. Dissertação (Mestrado) - FFLCH/USP, São Paulo, 2001.

TEIXEIRA, A. L. A.; CHRISTOFOlETTI, A. Sistemas de informação geográfica (Dicionário ilustrado). São Paulo: HUCITEC, 1997.

THOMAZ, E. L.; VESTENA, L. R. Aspectos climáticos de Guarapuava-PR. Guarapuava: UNICENTRO, 2003.

VIEIRA, L. S. Manual da ciência do solo: com ênfase aos solos tropicais. 2. ed. São Paulo: Agronômica Ceres Ltda, 1988. 